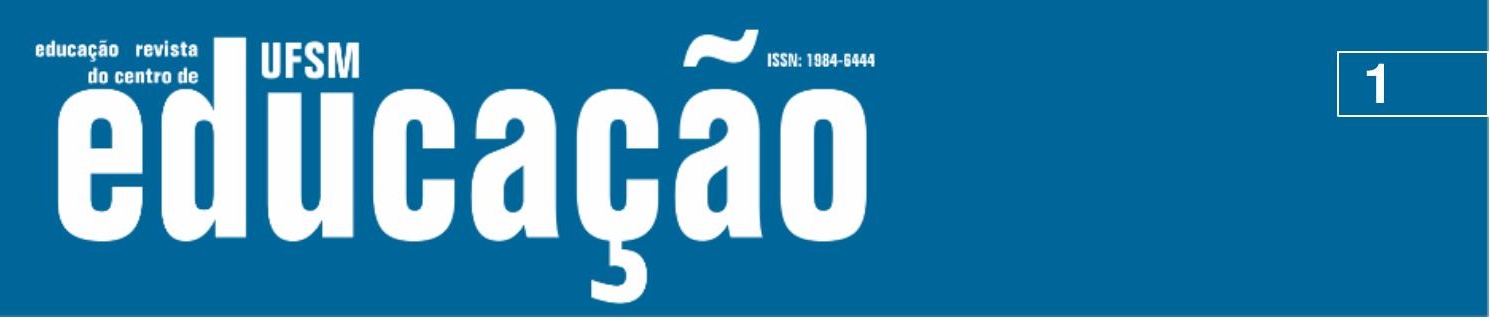

ISSN: 1984-6444 | http://dx.doi.org/10.5902/1984644436683

\title{
PROINFANTIL: a necessidade do programa e seu desenvolvimento
}

PROINFANTIL: the need for the program and its development

\footnotetext{
* Valéria Aparecida Benites de Oliveira Cabral

Mestranda na Universidade Federal de Mato Grosso do Sul, Corumbá, Mato Grosso do Sul, Brasil. valeriaaparecidab@hotmail.com

\section{** Anamaria Santana da Silva}

Professora aposentada da Universidade Federal de Mato Grosso do Sul. Campo Grande, Mato Grosso do Sul, Brasil.

anamariaufms@gmail.com
}

Recebido em 31 de janeiro de 2019

Aprovado em 20 de maio de 2019

Publicado em 15 de julho de 2019

\section{RESUMO}

O presente trabalho faz parte de pesquisa de mestrado (CPAN/UFMS) realizado no município de Corumbá-MS e consiste em descrever sobre as propostas de formação dos profissionais da Educação Infantil no Brasil e no estado de Mato Grosso do Sul com destaque ao programa PROINFANTIL - Programa de Formação Inicial para Professores em Exercício na Educação Infantil - cujos resultados obtidos indicaram que o Programa foi relevante por discutir temáticas imprescindíveis à reflexão e ao conhecimento de quem atua na área; além de motivar a equipe participante em investir na formação profissional. Para a realização deste estudo optou-se por um diálogo com o referencial teórico de autores como Barbosa (1991, 2003, 2011), Silva (1997), Kramer (2006), dentre outros; além da análise das propostas do material oferecido no programa. Como metodologia a pesquisa consistiu em levantamento bibliográfico e análise documental.

Palavras-chave: PROINFANTIL; Formação Profissional; Educação Infantil.

\section{ABSTRACT}

The present work is part of a master's research (CPAN / UFMS) carried out in the city of Corumbá-MS and consists of describing the proposals for the training of Child Education professionals in Brazil and in the state of Mato Grosso do Sul, with emphasis on the PROINFANTIL program - Initial Training Program for Teachers in Exercise in 


\section{A HEM Eulloaḩo}

ISSN: 1984-6444 | http://dx.doi.org/10.5902/1984644436683

Early Childhood Education whose results indicate that the Program was relevant for discussing topics essential to the reflection and knowledge of those who work in the area; besides motivating the participating team to invest in professional training. In order to carry out this study, we opted for a dialogue with the theoretical reference of authors such as Barbosa (1991, 2003, 2011), Silva (1997), Kramer (2006) among others; besides the analysis of the proposals of the material offered in the program. As methodology the research consisted of bibliographical survey and documentary analysis.

Keywords: PROINFANTIL; Professional Qualification; Child Education.

\section{Introdução}

Ao integrar a educação infantil como a $1^{\text {a }}$ etapa da educação básica, pode-se entender que a LDB 9394/1996 deu um novo significado ao ensino, dando início ao estabelecimento de critérios para credenciamento e funcionamento de instituições de educação infantil no Brasil a partir de 1997. Assim, acompanhar a trajetória do atendimento à criança de zero a seis anos e as significativas mudanças em termos legais com relação aos profissionais e suas práticas nas instituições, tem proporcionado aprofundar e refletir constantemente sobre as singularidades e especificidades da criança, de forma a respeitála enquanto cidadã de direitos, produtora de cultura e sujeito de sua história.

A partir desses enfoques, de avanços e das novas exigências à atuação com crianças pequenas, consideramos relevante explicitar, por meio desse estudo, 0 PROINFANTIL - Programa de Formação Inicial para Professores em Exercício na Educação Infantil; o qual foi um programa criado no conjunto das ações do Ministério da Educação e Cultura (MEC) como alternativa emergencial para superar o alto índice de profissionais da Educação Infantil sem a formação mínima exigida pela LDB; e proposto na perspectiva de atingir metas do Plano Nacional de Educação- PNE/20012011- Lei no 10.172 (BRASIL, 2001) que previa a habilitação de professores em exercício por meio da execução de Programas de Formação em Serviço em articulação com instituições de ensino superior e cooperação técnica e financeira da União e dos estados.

Embora estudos e pesquisas apontem dificuldades e contradições na qualidade (curso emergencial em nível médio e aligeirado) e na execução do programa em 


\section{口 Eutraaţa}

ISSN: 1984-6444 | http://dx.doi.org/10.5902/1984644436683

termos de investimentos financeiros e sobrecarga de conteúdos (por exemplo), identificados nos diversos estados e municípios em que fora desenvolvido, consideramos necessário refletir e considerá-lo enquanto política de formação de professores da Educação Infantil e enquanto resultado de ações em que concebe a formação profissional como necessária nas instituições infantis a partir das novas legislações que deram novos sentidos ao fazer pedagógico e ofereceu um leque de possibilidades, nas quais podemos citar: aprofundamento teórico, iniciação à pesquisa e reflexões sobre as ações desenvolvidas nas instituições infantis por meio de atividades coletivas e individuais exigidas no curso.

Para Oliveira (2010), a profissionalização dos educadores que atuam na educação infantil é um processo cultural que depende da função atribuída à creche e à pré-escola. Historicamente, ela afirma que a formação docente da área tem sido extremamente pobre ou inexistente, principalmente as do que trabalham em creches, área de muita atuação leiga e predominantemente feminina. Para a autora, isso ocorreu porque, dentro do quadro de marcantes desigualdades entre as diversas e antagônicas classes sociais existentes em nossa sociedade, a concepção assistencialista, tradicionalmente usada para nortear 0 trabalho nas creches (particularmente naquelas que atendem crianças filhas de famílias de baixa renda) fez com que pessoas sem qualificação profissional específica fossem recrutadas para cuidar e interagir com elas.

O "currículo oculto" a permear a (pouca) formação do pessoal recrutado envolveria apenas experiência e cuidado dos próprios filhos. Com isso esse modelo familiar/materno de cuidado e educação de crianças pequenas, nega a exigência de profissionalização, afirma Oliveira (2010). Assim, a partir desse entendimento, a nossa inquietação é persistente: por que mesmo com tantos avanços legais, sobretudo, na área da educação infantil, ainda hoje, não se prioriza a formação profissional na atuação com crianças pequenas? Por que grande parte dos municípios após esses avanços vêm utilizando práticas contraditórias de contratação de pessoas não habilitadas e com formação mínima de ensino fundamental?

Devemos entender que o aprimoramento da formação docente mudou significativamente e isso deve ser considerado; assim como a diversidade que está 


\section{工 WFH

ISSN: 1984-6444 | http://dx.doi.org/10.5902/1984644436683

presente na educação infantil não só em questões de número de crianças, de sua faixa etária ou em relação ao número de horas semanais em que a criança é atendida na instituição, mas, principalmente em relação à formação de seus profissionais e, posteriormente, aos objetivos defendidos e às programações de atividades efetivadas em seu cotidiano.

O presente artigo tem por objetivo descrever sobre as propostas de formação dos profissionais da Educação Infantil no Brasil e no estado do Mato Grosso do Sul e, com isso, destacar o programa PROINFANTIL enquanto política de formação importante e necessária aos profissionais que atuam junto a crianças pequenas.

\section{A formação dos profissionais da educação no Brasil}

A temática sobre a formação de profissionais tem obtido significativo espaço em discursos oficiais e em movimentos sociais no Brasil. Em determinados contextos e momentos históricos, a formação aparece associada ao debate sobre a qualidade do ensino e da educação, sendo concebida como um dos fatores que contribui com a promoção ou ausência da qualidade, afirma Barbosa (2011).

Isso significa que a formação do professor é reconhecidamente um dos fatores mais importantes para a promoção de padrões de qualidade adequados na Educação, seja em qualquer grau ou modalidade.

Barreto (1994) cita que, no caso da educação da criança pequena, vários estudos internacionais têm apontado que a capacitação específica do/a profissional é uma das variáveis que maior impacto causa sobre a qualidade do atendimento.

No Brasil, a relevância da questão tem levado vários/as estudiosos/as e profissionais que atuam na área a promover discussões e elaborar propostas para a formação do/a profissional de Educação Infantil, especialmente daqueles/as que trabalham em creches (BARRETO, 1994). Sobre essa questão, Kramer (2008) destaca: 
ISSN: 1984-6444 | http://dx.doi.org/10.5902/1984644436683

[...] a formação é necessária não apenas para aprimorar a ação profissional ou melhorara prática pedagógica. Tenho defendido a formação como direito a todos os professores/as: formação como conquista e direito da população, por uma escola pública de qualidade. Podem os processos de formação gerar ou desencadear mudanças? Considero que (como disse em outros lugares) as práticas concretas feitas nas creches, pré-escolas e escolas, e aquilo que sobre elas falam seus profissionais são o ponto de partida para as mudanças que se pretende implementar. $E$ elas são sempre feitas em conjunto. (KRAMER, 2006, p. 128).

Assim, por também considerarmos a formação como ponto determinante para a melhoria da qualidade educacional das instituições que atendem crianças de zero a seis anos, pretendemos discutir, nesse estudo, a importância da formação continuada e no trabalho para a reflexão da atuação de seus profissionais. Para tanto, a pesquisa consistiu no levantamento bibliográfico e análise documental.

Compreendendo a necessidade de formação dos profissionais que atuam com crianças pequenas e considerando a teoria e prática como elementos fundamentais ao conhecimento e a melhoria da qualidade no desenvolvimento do trabalho, entendemos, ser oportuno discutir essa temática afim de proporcionar ampla discussão e compreender a necessidade e importância da implementação de políticas de formação em nosso país.

No desenvolvimento desse estudo, optamos pela realização de uma pesquisa exploratória com abordagem qualitativa. Segundo Gil (1999), esse tipo de pesquisa exploratória tem como objetivo proporcionar maior familiaridade com o problema, com vista a torná-lo mais explícito ou a construir hipóteses. Seu planejamento é, portanto, bastante flexível, de modo que possibilite a consideração dos mais variados aspectos relativos ao fato estudado. Destacamos ainda que a pesquisa está pautada nas contribuições de autores como Barbosa (1991, 2003, 2011), Silva (1997, 2003), Kramer (2006), e produções científicas relacionadas aos temas políticas públicas e programas de formação; além da utilização de fontes de ordem legal correspondente ao amparo e proteção à infância. Tais fontes apresentam registros históricos e revelam algumas contradições presentes no campo da educação da criança pequena e da formação dos professores e outros profissionais da área.

Cabe destacar que procuramos nos pautar nos direitos da criança e na constituição legal que a ampara. Também, no campo deste estudo, optamos pela 


\section{HEM etithahá}

ISSN: 1984-6444 | http://dx.doi.org/10.5902/1984644436683

abordagem e discussão da pesquisa sob a ótica da esfera pública de atendimento, visto que o objeto de estudo resulta de um programa proposto pelo governo federal em parceria com os estados e municípios.

\section{Breve discussão sobre formação e primeira infância no Estado de Mato Grosso do Sul}

O Estado do Mato Grosso do Sul foi pioneiro na implantação de um fórum destinado a promover e discutir estratégias de ação voltadas para a Educação Infantil (E. I). Nos dias 20 e 21 de outubro do ano de 1994 foi realizado, no anfiteatro da Delegacia do MEC, o Seminário "Criança Cidadã" cujos participantes representaram instituições diversas (UFMS, LBA, DEMEC, CBIA, SEMCAS, SEBEM, APAE, PESTALOZZI, SEED, SEMED, OMEP/BR/MS, CEDCA, SESC, 1․ VARA DA INFÂNCIA E DA JUVENTUDE, SMEC-Corumbá), na qual, fora criado o "Fórum Permanente de Educação Infantil-MS" sob a coordenação da Professora Ordália Alves de Almeida. (ZANNINI, 2002).

Tal iniciativa resultou de um desejo coletivo das instituições envolvidas com a educação infantil em MS de realizar estudos, pesquisas, seminários, encontros e projetos de extensão, criando espaços de discussões sobre a criança de 0 a 6 anos, seus direitos, desejos, necessidades enquanto cidadãs. Além da fomentação de discussões sobre políticas de financiamento para a educação infantil, formação do profissional de educação infantil, dentre outras.

Nessa conjuntura, o Fórum Permanente de Educação Infantil do MS tem desenvolvido papel relevante, sobretudo, posicionando-se na necessidade de estruturação de políticas que enfatizem a formação de professores e a melhoria da qualidade do atendimento na educação infantil.

Sendo assim, no que tange a formação de professores, ao longo dos anos, o Fórum tem feito reflexões sobre o fazer docente atrelado à relação estabelecida entre conhecimento escolar e vida sociocultural. Trata-se do entendimento de que não basta realizar uma melhor formação, mas, de realizá-la de maneira diferente, contextualizada, exigindo mudança do próprio formador de modo que ele exerça um 


\section{口 Eutraaţa}

ISSN: 1984-6444 | http://dx.doi.org/10.5902/1984644436683

Em sua estrutura, ficou garantida uma abordagem voltada para os fundamentos teórico-práticos da educação infantil (zero a seis anos). (MIEIB, 2002).

Nesse processo de ênfase à primeira infância, as contribuições dos grupos de Estudos e Pesquisas desenvolvidas no âmbito das Unidades de Educação, na Capital e nos Campus do interior, da Universidade Federal de Mato Grosso do Sul, têm sido fundamentais na ampliação de debates, na união de forças e na reflexão de eixos temáticos comprometidos com a área. Dentre os vários grupos do campo da educação infantil, existentes no estado.

No Brasil, a OMEP foi a primeira instituição a defender políticas públicas voltadas à qualidade da Educação Infantil, em 1953. Tem contribuído, significativamente, com conquistas sociais brasileiras no que tange aos direitos das crianças (artigo 277 da Constituição Federal, Estatuto da Criança e do Adolescente, Constituições Estaduais, Leis Orgânicas, Diretrizes Curriculares Nacionais, entre outros) e à qualificação e valorização dos profissionais da Educação. (MOTTA, 2015).

O Estado de MS tem desenvolvido papel importante desde sua criação em 1982 aonde veio ampliando sua frente de ação, sobretudo, na realização de cursos, encontros e seminários. Estas ações têm, também, o objetivo de contribuir para a formação inicial e continuada, habilitação, qualificação e profissionalização de recursos humanos destinados à Educação, prioritariamente à Educação Infantil, e, também, é subsidiada por doações da sociedade civil e parcerias com a iniciativa privada e o poder público. (idem).

Destacando, também, na esfera pública, o papel da UEMS que, com base na investigação realizada sobre as reais necessidades e sobre o potencial de cada região do Estado (capital e 13 municípios), oferece o curso de Pedagogia com habilitação em pré-escola e séries iniciais do ensino fundamental. Com a imposição da LDBEN no 9394/96, essa universidade realizou, em fevereiro, o primeiro concurso vestibular para o Curso Normal Superior, com habilitação específica para o exercício do magistério da pré-escola. Sobre o conhecimento e a formação dos/as profissionais da educação infantil. Silva (2003) reforça: 
ISSN: 1984-6444 | http://dx.doi.org/10.5902/1984644436683

Os conhecimentos e a formação das profissionais da educação infantil foram se constituindo de formas diferenciadas: os/as profissionais de creche que adquiriram conhecimentos sobre a criança pequena criando um conjunto de práticas, com ênfase nos aspectos de higiene, saúde e comportamento. E as professoras das salas de jardim da infância ou pré-escolar que com formação inicial para o magistério trabalhavam com as crianças de 05 e 06 anos com o propósito de prepara-las para o processo de escolarização. No entanto, já existia uma demanda pela formação em serviço, projetos de extensão universitária, cursos promovidos por instituições como OMEP, LBA e outras entidades que se caracterizavam como cursos rápidos, de tendência pragmática, para aprender o que fazer. (SILVA, 2003, p. 37).

A autora reforça a evidência de uma dupla trajetória, também, na formação de professores: cursos específicos de formação em serviço e cursos de formação inicial para o magistério - curso normal e de pedagogia.

No entanto, é possível afirmar que a incorporação da formação de professores para a pré-escola nos cursos de formação para o magistério exerceu papel importante para a afirmação dessa modalidade de educação como um nível educacional. Também, nesse processo, modelos foram criados e ao mesmo tempo, questionados por diversos autores, reforça Silva (2003).

Desse modo, as instituições que oferecem cursos de Pedagogia sofreram, e vêm sofrendo, restruturações visando seu ajustamento de acordo com a Legislação em vigor, bem como de acordo com as Diretrizes Curriculares Nacionais para a Formação de professores da Educação Básica; reformulações estas importantes onde se ampliam as discussões sobre a formação de professores tanto em nível médio quanto superior e, sobretudo, questões referentes à qualidade do atendimento à criança de faixa etária de 0 a 5 anos. Assim, em Mato Grosso do Sul:

Constata-se que não existe apenas a preocupação com a formação superior do professor de educação infantil, mas, sobretudo, o que ela realiza, efetivamente, há 20 anos. Historicamente, este Estado tem buscado romper com a tradição assistencialista da educação infantil, preocupando-se em profissionalizar aqueles que atuam diretamente com a criança (ZANNIN, 2002, p. 59).

Como vimos preocupar-se com a formação superior do professor é algo muito importante, no entanto, sabemos que, nos últimos anos, a formação profissional tem apresentado concepções contraditórias onde se constata que mais importância se dá às propostas de formação do que à maneira como os professores aprendem; como é o caso dos projetos de formação aligeirados, de formação técnico-profissionalizante 


\section{HEM etíthará}

ISSN: 1984-6444 | http://dx.doi.org/10.5902/1984644436683

sem espaço para reflexão.

Em meio a essas discussões, sobre formação de professores, em nível superior, surge o Programa de Formação Inicial para Professores em exercício na Educação Infantil - PROINFANTIL, em 2005, um curso, em nível médio, na modalidade Normal, com objetivo de qualificação dos professores que atuam na Educação Infantil; colocando assim, contradições e choques desse modelo de formação, que se colocam como desafios fundamentais quando se pensa no estabelecimento de uma política de profissionalização desses sujeitos.

\section{Bases legais e teóricas do Programa PROINFANTIL}

Primeiramente, cabe destacar que o PROINFANTIL é um Projeto do Ministério da Educação brasileiro, criado em 2004 e implementado em 2005, em parceria com a Secretaria de Educação Básica (SEB) e a Distância (SEED). Foi um curso ministrado, em todo território nacional, num período de seis anos (de 2005 a 2011) que teve como parceiros, estados e municípios; cabendo a cada ente federado diferentes responsabilidades, definidas nas Diretrizes Gerais do Programa (BRASIL, 2005a) e estabelecidas em Acordo de Participação, assinado pelas três instâncias envolvidas: esfera federal, estadual e municipal.

O PROINFANTIL - Programa de Formação Inicial para Professores em Exercício na Educação Infantil - foi um curso semipresencial de nível médio, na modalidade Normal. O programa foi destinado aos professores em exercício na Educação Infantil das redes públicas, privadas ou filantrópicas que não possuíam formação específica para o magistério. No entanto, os vários estados optaram pelo oferecimento do curso apenas às instituições públicas. O PROINFANTIL foi um curso criado nos mesmos moldes e com objetivos similares ao Programa de Formação de Professores em Exercício nos Anos Iniciais do Ensino Fundamental PROFORMAÇÃOi, ou seja, apresentou as mesmas características e organização estrutural do mesmo. A diferença está em seu público-alvo (conforme acima destacado) e em suas especificidades curriculares das áreas pedagógicas. 


\section{工 WFM Eutinaba}

ISSN: 1984-6444 | http://dx.doi.org/10.5902/1984644436683

Com duração de dois anos, o Programa teve como objetivos habilitar e qualificar os professores da educação infantil, elevar o nível de conhecimento, aprimorar a prática pedagógica dos docentes em exercício, oferecer condições de crescimento profissional e pessoal, dentre outros (BRASIL, 2005a). Seu objetivo maior era agilizar o cumprimento da Lei de Diretrizes e Bases da Educação Nacional (LDBEN 9.394/96) que atribuía aos Municípios, Estados e União, a incumbência de realizar programas de formação para todos os professores em exercício, com utilização de recursos da educação a distância (Art.87, \&3ํ, inciso III).

O Plano Nacional de Educação (PNE 2001/2010) veio para estabelecer diretrizes político-pedagógicas comuns à creche e à pré-escola e determinar o atendimento, até 2011 , de $50 \%$ das crianças de 0 a 3 anos e de $80 \%$ das crianças de 4 a 6 anos; além da determinação de que todas as instituições de educação infantil tenham seus Projetos Pedagógicos e de que sejam estabelecidos parâmetros de qualidade em seus serviços, como instrumento para a adoção de medidas na melhoria da qualidade, ou seja, que sejam estabelecidos critérios de admissão de novos profissionais para esta etapa da Educação Básica.

Camargo (2012) afirma que essa preocupação com a formação profissional foi discutida, também, na Conferência Nacional de Educação realizada em 2010 onde trouxe à discussão o Sistema Nacional Articulado de Educação, sobretudo, apresentado no eixo IV da CONAE, que se refere à Formação e Valorização dos Profissionais da Educação como facetas da política nacional e que deveriam ser consideradas indissociáveis (CAMARGO, 2012, p. 6).

Contudo, embora a formação docente na educação básica deva ser priorizada em nível superior para o exercício do magistério, a LDB (Lei nº 9.394/96), deixa uma abertura, ao admitir a formação em nível médio, na modalidade normal, conforme o artigo 62 (questão essa que motivou muitas críticas ao programa):

Art.62. A formação de docentes para atuar na educação básica far-se-á em nível superior, em curso de licenciatura, de graduação plena, em universidades e institutos superiores de educação, admitida, como formação mínima para o exercício do magistério na educação infantil e nas quatro primeiras séries do ensino fundamental, a oferecida em nível médio, na modalidade Normal (BRASIL, 1996, s. p.). 


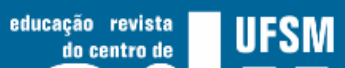 Eutuab̧a}

ISSN: 1984-6444 | http://dx.doi.org/10.5902/1984644436683

Como defesa e apoio a essa ideia, de formação de professores em nível médio, a Câmara de Educação Básica do Conselho Nacional de Educação (CEB/CNE) também se posicionou a favor dessa modalidade de ensino por meio do parecer $3 / 2003$ e da resolução 1/2003 onde se declara a favor dos direitos dos profissionais que atuam na Educação Infantil e nos anos iniciais do Ensino Fundamental:

A redação do artigo 62 da LDB é clara e não deixa margem para dúvida. Aqueles que frequentam um curso normal, de nível médio, praticam um contrato válido com a instituição que o ministra. Atendidas as disposições legais pertinentes, a conclusão desse curso conduz a diploma que, por ser fruto de ato jurídico perfeito, gera direito. No caso, o direito gerado é a prerrogativa do exercício profissional, na educação infantil e nos anos iniciais do Ensino Fundamental. (BRASIL, 2005a, p. 8).

Além disso, a Resolução CNE/CEB 01/2003 dispõe em seu artigo 1ำ que:

Os sistemas de ensino, de acordo com o quadro legal de referência, devem respeitar em todos os atos praticados os direitos adquiridos e as prerrogativas profissionais conferidas por credenciais válidas para o magistério na educação infantil e nos anos iniciais do Ensino Fundamental, de acordo com o disposto no art. 62 da Lei 9394/96. (BRASIL, 2005, p. 8).

E em seu artigo $2^{\circ}$, reforça:

Os sistemas de ensino envidarão esforços para realizar programas de capacitação para todos os professores em exercício.

$\S 1^{\circ}$. Aos docentes da educação infantil e dos anos iniciais do ensino fundamental será oferecida formação em nível médio, na modalidade Normal até que todos os docentes do sistema possuam, no mínimo, essa credencial. (BRASIL, 2005, p. 8).

É dessa forma que o PROINFANTIL se configurou como um curso emergencial (e dito, aligeirado) que apresenta em sua proposta pedagógica um currículo baseado em eixos integradores e interdisciplinar objetivando a articulação dos conteúdos do curso às experiências do/as cursistas e às especificidades do trabalho docente na Educação Infantil (BRASIL, 2005b).

Portanto, para atingir metas do PNE 2001-2010 cujas intenções, eram a de habilitar professores em exercício, efetivar programas de formação em serviço em articulação com instituições de ensino superior e em cooperação técnica e financeira da União e dos estados, o Ministério da Educação sugere o PROINFANTIL; impondo que os sistemas de ensino oferecessem a formação em nível médio, na modalidade tradicional, até que todos os docentes possuíssem no mínimo essa habilitação 


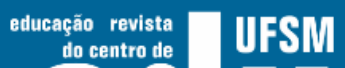 entuabal}

ISSN: 1984-6444 | http://dx.doi.org/10.5902/1984644436683

conforme já registrado. Outra de suas metas era ter todos os profissionais que atuam na área de Educação Infantil e nas séries iniciais do Ensino Fundamental, com formação em nível médio até 2006; e 70\% com formação superior até 2011.

Segundo as Diretrizes Gerais (2005, p. 6) os requisitos exigidos para ingresso no curso eram: ter idade mínima de 18 anos; vínculo empregatício; tempo de serviço e atuação com crianças de pelo menos seis meses. O curso foi semipresencial na modalidade de ensino a distância com duração de dois anos, compreendidos em quatro módulos semestrais perfazendo um total de 3392 horas. Cada módulo correspondeu a 848 horas distribuídas em: Fases Presenciais; Atividades Individuais; Encontros Quinzenais (aos sábados); Prática Pedagógica; Língua Estrangeira e Projeto de Estudo.

Para melhor entendimento, de sua estrutura organizacional e atribuições de cada um de seus componentes, o programa ofereceu um Guia Geral, publicado em 2005 e 2008, destinado, sobretudo, às professoras cursistas (PC) onde contém informações básicas sobre o curso. Sobre o Guia Geral, Barbosa, Soares e Gonçalves (2011) descrevem:

O Guia está dividido em oito seções e um Anexo, que traz um 'Modelo de identificação da proposta de Projeto de Estudo'. As informações e orientações são apresentadas ao professor cursista (PC) nas oito seções que abrangem: informações sobre o PROINFANTIL; perfil do professor que deseja formar; proposta pedagógica do curso; informações sobre as atividades metodologia do curso; sistema de apoio à aprendizagem - informações sobre a AGF e seu Tutor; informações sobre o processo de avaliação do PROINFANTIL e da avaliação de sua aprendizagem; orientação ao professor Cursista (PC) para o estudo; tira-dúvidas. (BARBOSA, 2011, p. 318).

Como vimos, o Guia Geral foi uma publicação que continha informações e orientações gerais do curso seguido de momentos de esclarecimentos de dúvidas. No entanto, Barbosa (2011), ressalta que o MEC deixou de citar, nesse documento, modificações importantes (como Componente Nacional) que foi o papel das universidades federais, que passaram a atuar no programa desde 2007.

Além desta publicação citada, Barbosa (idem) destaca como publicações importantes do programa, o Livro do Tutor publicado em 2005, que trata-se de um material de orientações ao Tutor (TR), com definições de seu papel e 


\section{工 WFH enturará}

ISSN: 1984-6444 | http://dx.doi.org/10.5902/1984644436683

responsabilidades em todas as etapas do curso; e os Textos de apoio ao trabalho do Tutor publicados em 2007 que se refere a uma coletânea de textos envolvendo temáticas diversas que dizem respeito à escrita de memorial do professor, à observação da prática e de intervenção, ao planejamento, registro, reflexão, ao trabalhos nos Encontros Quinzenais e em específico, ao trabalho com os bebês desenvolvidos nas instituições infantis (creche); material esse, elaborados por especialistas da área da educação infantil, com experiência na formação de professores.

O Currículo do curso foi organizado em áreas temáticas congregando a Base Nacional Comum do Ensino Médio e Formação Pedagógica, contemplando assim, a Base Nacional Comum do Ensino Médio e as disciplinas: a) linguagens e códigos; b) identidade, sociedade e cultura; c) matemática e lógica; e d) vida e natureza. Por sua vez, a Formação Pedagógica estava constituída pelas disciplinas de: a) fundamentos da educação; b) organização do trabalho pedagógico; e c) língua estrangeira moderna.

Para operacionalização deste Currículo, o curso foi organizado metodologicamente por meio da oferta de atividades à distância, orientadas através de material impresso e vídeo-gráfico, e atividades presenciais concentradas nos períodos de férias escolares (fases presenciais) e aos sábados (encontros quinzenais); havendo também, o desenvolvimento de atividades de prática pedagógica nas instituições em que os/as professores/as cursistas atuam sendo acompanhadas e orientadas pelo tutor (TR), que acompanhavam o trabalho desenvolvido durante o período letivo (BARBOSA, 2001).

Os materiais auto instrucionais foram divididos em dois volumes compostos por:

- 34 livros de estudo das áreas temáticas do ensino médio, contendo textos para os estudos individuais;

- 32 livros de estudo das áreas pedagógicas da Educação Infantil, fundamentos da educação e organização do trabalho pedagógico; e 


\section{工 WFH eutloarao}

ISSN: 1984-6444 | http://dx.doi.org/10.5902/1984644436683

- 32 cadernos de aprendizagem, contendo exercícios com base nos livros de estudos.

As atividades coletivas presenciais, de acordo com as Diretrizes Gerais (BRASIL, 2005, p. 11) eram assim distribuídas:

- Fase Presencial (FP) - contendo 76 horas de atividades presenciais;

- Encontro Quinzenal - contendo 64 horas divididas em 8 encontros presenciais durante cada módulo (realizados no próprio município em local disponibilizado pelo órgão);

- e Fase Presencial Intermediária: 20 horas de atividades presenciais realizadas durante cada módulo e coordenadas pelos professores formadores das Agências Formadoras (sendo as vinte horas de cada módulo distribuídas em dois encontros que antecediam as provas bimestrais).

Nas atividades individuais a Professora Cursista (PC) tinha a responsabilidade de desenvolver uma série de tarefas durante o desenvolvimento do curso:

- estudo individual, atividades de estudo (estudos a serem respondidos no caderno de aprendizagem com base nos conteúdos das áreas temáticas);

- registro reflexivo (instrumento de auto avaliação);

- elaboração de portfólio (instrumento voltado para as disciplinas pedagógicas);

- planejamento diário (elaborado para ser aplicado em sala e observado pelo/a tutor/a em sua visita mensal);

- escrita de memorial (escrita livre de vivências ao longo do curso);

- registro das atividades (reflexão sobre uma atividade interessante desenvolvida com as crianças);

- prática pedagógica (atividade desenvolvida com a criança na instituição de atuação do/a cursista com acompanhamento do tutor);

- provas bimestrais (prova individual, sem consulta, realizada duas vezes em cada módulo); e, atividades extras de estudo, que funcionam, no programa, como momento de revisão, esclarecimento de dúvidas e de recuperação.

Conforme apresentamos são muitos os documentos que registram todo o 


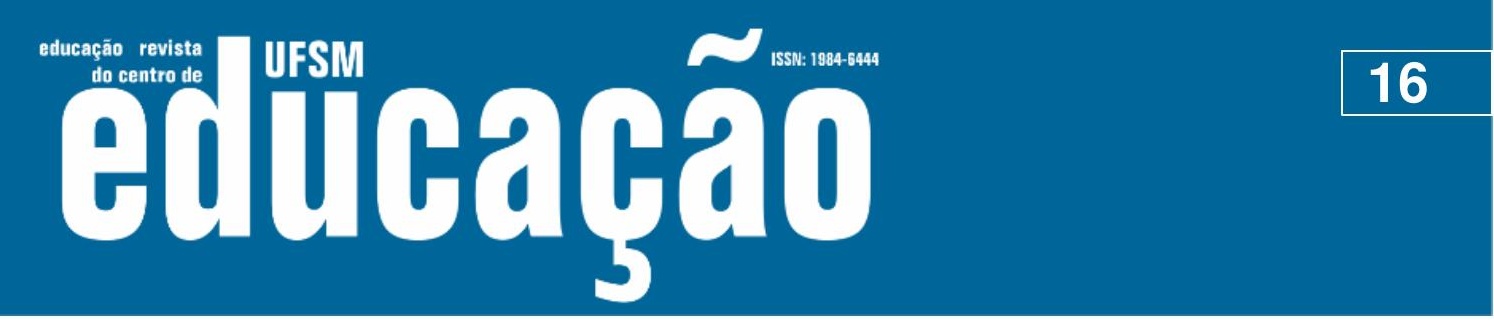

ISSN: 1984-6444 | http://dx.doi.org/10.5902/1984644436683

processo de criação do curso e condição para seu desenvolvimento. Fazendo referência sobre a aprendizagem consideramos importante destacar:

[...] há necessidade de se entender que aprender é um processo complexo, onde o ser humano deve ser o sujeito ativo na construção do conhecimento, e que este só se dá a partir da ação do sujeito sobre a realidade. O conhecimento é o principal fator de inovação disponível ao ser humano. $O$ conhecimento não é constituído de verdades estáticas, mas de um processo dinâmico, que acompanha a vida humana e não constitui em mera cópia do mundo exterior, sendo um guia para ação. Ele emerge da interação social e tem como característica fundamental poder ser manifestado e transferido por intermédio da comunicação. Assim, a capacidade de aprender, de desenvolver novos padrões de interpretação e de ação, depende da diversidade e da natureza do conhecimento. (BELLUZZO apud SOUZA, 2007, p. 59).

Conforme vimos, o material oferecido pelo programa PROINFANTIL apresenta eixos integradores com conteúdos específicos do trabalho docente em educação infantil. Barbosa (2011, p. 392) destaca que sua proposta pedagógica propõe o trabalho com base em eixos integradores e na interdisciplinaridade, havendo a expectativa de se articular os conteúdos do curso às experiências dos professores cursistas e às especificidades do trabalho docente em educação infantil.

Isso demonstra que são muitos os documentos que registram todo o processo de criação do curso; além das várias leis e diretrizes que o fundamentam e autorizam. A implantação do programa se deu em parcerias entre união, estados e municípios; cada ente federado com diferentes responsabilidades, todas definidas previamente nas Diretrizes Gerais do Programa e registradas em Acordo de Participação assinado pelas três instâncias envolvidas. Componente nacional é responsável pela elaboração da proposta técnica, pedagógica e financeira; componente estadual, responsável pela implementação, acompanhamento e monitoramento do Programa no âmbito do estado; e componente municipal, responsável pela implementação do programa no âmbito municipal onde faz parte os seguintes componentes: Secretaria municipal de Educação, Órgão Municipal de Educação- OME e Corpo de Tutores (TR).

Em novembro de 2007, o MEC permitiu que as Instituições de Ensino Superior (IES), assumissem a coordenação, acompanhamento e formação em seus Estados, significando um grande avanço ao programa.

No entanto, a participação das Instituições de Ensino Superior (IES) no 


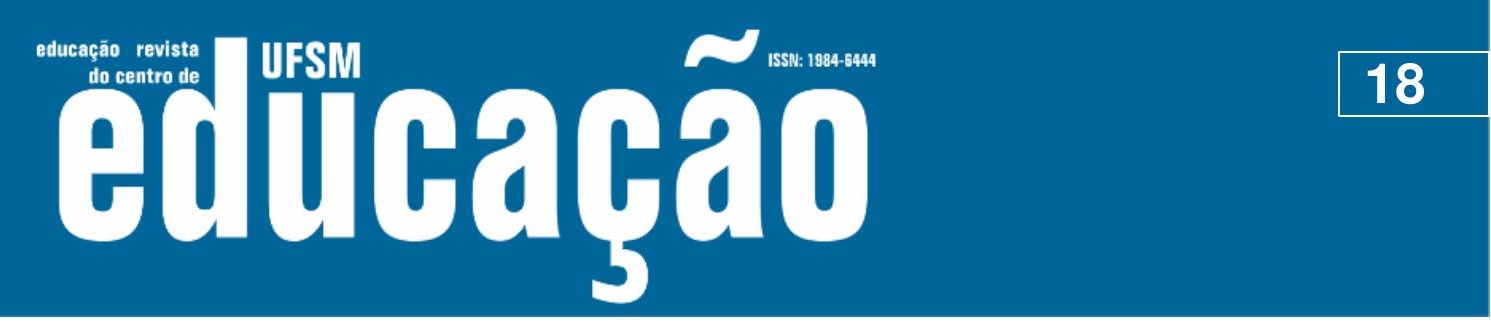

ISSN: 1984-6444 | http://dx.doi.org/10.5902/1984644436683

os professores envolvidos, com exceção do professor cursista.

Nogueira (2014, p. 75) destaca que:

Em 2011, ano em que Dilma Rousseff assumiu a Presidência da República, houve algumas modificações organizacionais no governo, e é claro que a reorganização também atingiu o MEC.

Entre as mudanças ocorridas, no Ministério da Educação, destacamos as que interferiram diretamente no PROINFANTIL. A Secretaria de Educação a Distância foi extinta, fato que implicou o retorno da coordenação do PROINFANTIL à Secretaria de Educação Básica, sendo ligada diretamente à Diretoria de Apoio à Gestão Educacional (DAGE/SEB). (NOGUEIRA, 2014, p. 75).

Conforme visto, o programa PROINFANTIL passou por diversos processos: desde sua formulação, implementação e desenvolvimento. Uns considerados avanços, outros retrocessos. Um dos pontos considerados retrocessos pode ser destacado como a finalização do programa que cerceava de expectativas pelos/as profissionais e equipe técnica pedagógica envolvidas em cada município. De acordo com dados do Sistema de Informação do PROINFANTIL(SIP), o programa previa o ingresso de mais 20.000 professores, com a implantação do Grupo IV e adesão de todos os Estados da federação. No entanto, até o início de 2013 nenhuma ação concreta para a continuidade do Programa pelo MEC.

\section{PROINFANTIL no Estado de Mato Grosso do Sul}

O PROINFANTIL começou a ser gestado em Mato Grosso do Sul em 2007, momento em que o Ministério da Educação estabeleceu parcerias com as Instituições de Ensino Superior (IES) para que as mesmas passassem a coordenar as ações do programa nos Estados, conforme já destacado.

Nogueira (2014) destaca a importante participação da Universidade Federal de Mato Grosso do Sul em termos de articulações e parceria com o MEC para viabilização do programa no estado:

No período de 2007 a 2009, as coordenadoras do Programa no Estado, professoras Doutoras Ordália Alves Almeida e Regina Aparecida Marques de Souza, da Universidade Federal de Mato Grosso do Sul começaram a articular algumas ações em parceria com o MEC, para viabilizar a implantação do PROINFANTIL no Estado. A necessidade do Programa foi posta por meio de um ofício elaborado pela Secretaria de Assistência Social, apresentando uma demanda de mil profissionais leigos. (NOGUEIRA, 2014, 


\section{X

ISSN: 1984-6444 | http://dx.doi.org/10.5902/1984644436683

p. 76).

De acordo com o levantamento de dados de Nogueira (2014 p.76) a Secretaria Estadual de Mato Grosso do Sul (SED) realizou a pré-inscrição de 426 professores cursistas em 28 municípios do estado. Contudo, somente foram efetivados 389 participantes distribuídos em 25 municípios. Para atender essas pessoas, implementaram-se quatro Agências Formadoras (AGF): Aquidauana, Campo Grande, Fátima do Sul e Três Lagoas.

Para melhor entendimento do funcionamento dessas AGFs segue a apresentação do seguinte quadro contendo a distribuição dessas Agências formadoras no estado de MS:

Quadro 1 - Agência Formadora de MS

\begin{tabular}{|l|c|c|c|c|c|}
\hline $\begin{array}{c}\text { AGÊNCIA } \\
\text { FORMADORA }\end{array}$ & $\begin{array}{c}\text { QUANTIDADE } \\
\text { DE } \\
\text { MUNICÍPIOS }\end{array}$ & $\begin{array}{c}\text { QUANTIDADE } \\
\text { DE TUTORES } \\
\mathbf{( 2 0 0 9 )}\end{array}$ & $\begin{array}{c}\text { PROFESSORES } \\
\text { CURSISTAS } \\
\text { INICIANTES }\end{array}$ & $\begin{array}{c}\text { QUANTIDADE } \\
\text { DE TUTORES } \\
\mathbf{( 2 0 1 1 )}\end{array}$ & $\begin{array}{c}\text { PROFESSORES } \\
\text { CURSISTAS } \\
\text { FORMADOS }\end{array}$ \\
\hline Aquidauana & 08 & 13 & 132 & 13 & 124 \\
\hline Campo Grande & 05 & 08 & 86 & 08 & 77 \\
\hline $\begin{array}{l}\text { Fátima do } \\
\text { Sul }\end{array}$ & 08 & 10 & 98 & 09 & 70 \\
\hline Três Lagoas & 04 & 08 & 73 & 06 & 47 \\
\hline Total & 25 & 39 & 389 & 36 & 318 \\
\hline
\end{tabular}

Fonte: Sistema de Informação do PROINFANTIL, pesquisa realizada no primeiro semestre de 2013.

É interessante que esse quadro nos dá uma visibilidade do funcionamento organizacional do programa no estado de MS com destaque do quantitativo de cursistas que ingressaram no programa e formadas no mesmo.

Em sua pesquisa Nogueira (2014) apresenta importante contribuição sobre alguns impasses do desenvolvimento do programa no estado de MS:

Alguns momentos do caminho percorrido para a implantação e implementação do Programa no Estado precisam ser enfatizados, um deles foi o não cumprimento de elementos estabelecidos no Guia Geral e nas Diretrizes Gerais do PROINFANTIL, tais como a fase presencial 
ISSN: 1984-6444 | http://dx.doi.org/10.5902/1984644436683

intermediária, que não aconteceu, e a contratação do articulador pedagógico da Educação Infantil, que se efetivou apenas no módulo III. O atraso do material didático (Livros de Estudo das Áreas Temáticas do Ensino Médio e das Áreas Pedagógicas e os Cadernos de Aprendizagem), na primeira fase presencial e a ausência do material de Língua Estrangeira Espanhol, nos módulos II e III, prejudicaram o desenvolvimento das atividades. (NOGUEIRA, 2014, p. 77).

Outra referência feita por Nogueira (2014, p. 77) se refere a constituição do Grupo de Estudos do PROINFATIL (GEPROIN), organizado pela UFMS por meio de uma agenda mensal, em que se discutiam textos referentes à Educação Infantil objetivando fortalecer e embasar debates entre os professores formadores e tutores nas AGFs. Para Nogueira (2014), esse foi um elemento que diferenciou o estado dos demais e contribuiu com a formação dos participantes, uma vez, que nos outros estados o estudo não era direcionado e nem acompanhado pelas universidades.

De forma mais específica, o quadro abaixo nos apresenta os números de cursistas e Tutores/as envolvidos/as na AGF Aquidauana considerada a Agência formadora maior do Estado em número de cursistas e tutores:

Quadro 2 - Agência Formadora de Aquidauana

\begin{tabular}{|l|c|c|c|c|}
\hline $\begin{array}{c}\text { MUNICÍPIOS } \\
\text { PARTICIPANTES }\end{array}$ & $\begin{array}{c}\text { QUANTIDADE } \\
\text { DE TUTORES } \\
\mathbf{( 2 0 0 9 )}\end{array}$ & $\begin{array}{c}\text { PROFESSORES } \\
\text { CURSISTAS } \\
\text { INICIANTES } \\
\mathbf{( 2 0 0 9 )}\end{array}$ & $\begin{array}{c}\text { QUANTIDADE } \\
\text { DE TUTORES } \\
\mathbf{( 2 0 1 1 )}\end{array}$ & $\begin{array}{c}\text { PROFESSORES } \\
\text { CURSISTAS } \\
\text { FORMADOS } \\
\mathbf{( 2 0 1 1 )}\end{array}$ \\
\hline Aquidauana & 01 & 11 & 01 & 09 \\
\hline Bodoquena & 01 & 10 & 01 & 10 \\
\hline Bonito & 01 & 08 & 01 & 08 \\
\hline Corumbá & 03 & 34 & 03 & 33 \\
\hline Jardim & 02 & 13 & 02 & 11 \\
\hline Ladário & 01 & 13 & 01 & 11 \\
\hline Porto Murtinho & 03 & 29 & 03 & 124 \\
\hline Miranda & 01 & 13 & 01 & 13 \\
\hline TOTAL & 13 & 132 & & \\
\hline
\end{tabular}

Fonte: NOGUEIRA, 2014, p. 77. 


\section{工 WFH etituará}

ISSN: 1984-6444 | http://dx.doi.org/10.5902/1984644436683

O quadro apresenta poucas alterações e segundo Nogueira $(2014,78)$, essa também foi a Agência em que houve menor número de professores que não concluíram o curso. De acordo com o SIP não houve reprovação durante o processo, no entanto, oito cursistas desistiram do curso. As desistências não ocorreram em um único município, como apresentado no quadro $\mathrm{V}$, mas foram distribuídas entre cinco municípios, sendo eles: Aquidauana (2), Corumbá (1), Jardim (1), Porto Murtinho (2) e Miranda (2) (NOGUEIRA, 2014, p. 78). Podemos observar que, na AGF Aquidauana, a equipe se manteve quase a mesma até a conclusão do curso.

Vale destacar que a partir do que foi apresentado sobre o PROINFANTIL, que o curso em termos metodológicos e curriculares se diferenciou de muitos outros Programas de formação: ele se distancia dos moldes tradicionais que priorizavam, sobretudo, o fazer técnico e a instrumentalização desses fazer. Além disso, o PROINFANTIL teve equipes especializadas, selecionadas por qualificação.

Em relação à formação de profissionais de Educação Infantil, consideramos que o PROINFANTIL conseguiu se destacar na história da educação por suas características e especificidades, dando a oportunidade para o estabelecimento de estreita relação entre sujeitos, realidade concreta e construção reflexiva do conhecimento.

\section{Considerações finais}

Apesar do PROINFANTIL se configurar como um curso emergencial, de característica aligeirada e em modalidade normal (não condizentes com as atuais exigências de um curso de formação: formação em nível superior) e apresentar dificuldades de ordem administrativa/financeira em seu desenvolvimento, consideramos que o programa apresentou indícios de formação bem-sucedida e de cumprimento com o papel formativo, contudo, no âmbito das políticas não criou ações que garantissem a valorização do trabalho dessas cursistas formadas; conforme apontam os resultados.

Como participante do programa na função de Tutora, pudemos conhecer, 
